University of Wollongong

Research Online

SMART Infrastructure Facility - Papers

Faculty of Engineering and Information

Sciences

$1-1-2014$

Cross-cultural leadership in the implementation of systems engineering

processes: a study of Indonesian expatriate engineers

Ika S. Windiarti

University of South Australia

Timothy L.J Ferris

University of South Australia

Matthew J. Berryman

University of Wollongong, mberryma@uow.edu.au

Follow this and additional works at: https://ro.uow.edu.au/smartpapers

Part of the Engineering Commons, and the Physical Sciences and Mathematics Commons

Research Online is the open access institutional repository for the University of Wollongong. For further information contact the UOW Library: research-pubs@uow.edu.au 


\title{
Cross-cultural leadership in the implementation of systems engineering processes: a study of Indonesian expatriate engineers
}

\author{
Abstract \\ In projects involving engineers from multiple cultural backgrounds the implementation of Systems \\ Engineering (SE) Processes demands cross-cultural leadership competence by the engineers who lead \\ such work teams to support the quality of project performance. This paper reports the qualitative results \\ of a web-based survey of Indonesian expatriate engineers addressing their perceptions of cross-cultural \\ issues in the implementation of SE processes in projects. The questions investigated the engineers' \\ knowledge, experience, and perception of how they manage the leadership aspect of their intercultural \\ relationships. Several issues were identified as factors influencing cross-cultural leadership. The factors \\ that influence cross-cultural leadership include conflict resolution and decision making styles used by the \\ project leader. This study reveals that, as perceived by Indonesian engineers, the conflicts that happen in \\ the project team were resolved based on existing policy rather than considering the specific cultural \\ background of participants and the important decisions in the project team were made collaboratively \\ using the leader's ideas and members' contributions. Another result from this study is that the \\ relationships between team members were important to the achievement of an effective balance \\ between the completeness and quality of the project. This paper discusses how intercultural issues \\ interact with performance of formally defined project processes. \\ Disciplines \\ Engineering | Physical Sciences and Mathematics

\section{Publication Details} \\ Windiarti, I. S., Ferris, T. L. J. \& Berryman, M. J. (2014). Cross-cultural leadership in the implementation of \\ systems engineering processes: a study of Indonesian expatriate engineers. 8th Annual IEEE International \\ Systems Conference (SysCon) (pp. 337-344). United States: IEEE.
}




\section{Cross-cultural Leadership in the Implementation of Systems Engineering Processes: A Study of Indonesian Expatriate Engineers}

\author{
Ika S. Windiarti ${ }^{1,2 *}$ \\ ${ }^{1}$ Defence and Systems Institute, \\ University of South Australia, Australia \\ ${ }^{2}$ Tridharma University, Indonesia \\ Email: winis001@mymail.unisa.edu.au
}

\author{
Timothy L.J. Ferris ${ }^{1^{*}}$ \\ ${ }^{1}$ Defence and Systems Institute, \\ University of South Australia \\ Adelaide, Australia \\ Email: timothy.ferris@unisa.edu.au
}

\author{
Matthew J. Berryman ${ }^{1,3 *}$ \\ ${ }^{1}$ Defence and Systems Institute, \\ University of South Australia \\ ${ }^{3}$ SMART Infrastructure Facility, \\ University of Wollongong, Australia \\ Email: mberryma@uow.edu.au
}

\begin{abstract}
In projects involving engineers from multiple cultural backgrounds the implementation of Systems Engineering (SE) Processes demands cross-cultural leadership competence by the engineers who lead such work teams to support the quality of project performance. This paper reports the results of a web-based survey of Indonesian expatriate engineers addressing their perceptions of cross-cultural issues in the implementation of SE processes in projects. The questions investigated the engineers' knowledge, experience, and perception of how they manage the leadership aspect of their intercultural relationships. Several issues were identified as factors influence cross-cultural leadership. Those factors that influence cross-cultural leadership including conflict resolution and decision making styles used by the project leader. This study reveals that, as perceived by Indonesian engineers, the conflicts that happen in the project team were resolved based on existing policy rather than considering the specific cultural background and the important decisions in the project team were made by collaboration using the leader's ideas and members' contributions. Another result from this study is that the relationships between team members were important to the achievement of an effective balance between the completeness and quality of the project. This paper discusses how intercultural issues interact with performance of formally defined project processes.
\end{abstract}

Keywords - cross-cultural; leadership; Indonesian engineers; Systems Engineering

\section{INTRODUCTION}

Projects are often performed by people from diverse cultural backgrounds. The ability of engineers to manage and work in these cross-cultural teams includes cross-cultural leadership ability. Cross-cultural leadership competence for the engineers supports the quality of the project performance.

Cross-cultural leadership is needed for teams coming from different countries with their own cultural characteristics. There are two major aspects in cross-cultural leadership [1]. The first aspect is the manager's adjustment of their leadership style when they engage with subordinates of different cultural backgrounds. Those who have cross-cultural leadership competencies will simply change their style of managersubordinate interaction. The second aspect of cross-cultural leadership is the subordinates' acknowledgment of the manager's adjustment of leadership style [1]. In the latter aspect the subordinates recognize the adjustments that the manager has made. This aspect is more individually focused on the subordinates' interpersonal communication skills than the former aspect.

The purpose of this paper is to identify how the subordinates perceive cross-cultural leadership in their projects in implementing SE processes and their implications in the improvement of cross-cultural leadership capability.

This study reports the perception of Indonesian engineers of conflict resolution in engineering project teams which was primarily resolved using existing rules rather than considering the cultural background. This study also reveals that the important decisions in the project team were made by collaboration of leader's ideas and member's contributions in analyzing the supporting ideas. Another result from this study 
is that the relationships between team members are important to the success of the organization.

\section{METHODOLOGY}

This paper reports results from the second phase of a research project. The first phase was a small set of interviews with engineers to explore the conceptual space associated with the questions under investigation, with a view to refining the questions presented in the survey reported here. The earlier phase has been reported in other papers [2, 3]. This work has been conducted under human research ethics protocols approved by University of South Australia (Ethics Protocol Number 0000023567. "Cross-cultural Impacts on Systems Engineering Practices -Main Study").

\section{A. Sampling Method}

The population was sampled using purposive sampling. The research participants were invited to participate because they were Indonesian engineers working in other countries with over six months experience in the other country. The participants were found using social networking and professional society membership. A deliberate effort was made to obtain participants working in a variety of countries to which many Indonesian engineers travel for work. Potential research subjects were contacted by email and phone to describe the research and to offer the opportunity to contribute to this study.

\section{B. Questionnaire}

The questionnaire used in this study contained both closed and opened-ended questions. The open-ended questions were designed to elicit detailed descriptions to identify the participants' experience and knowledge associated with the research topic.

\section{Research Participants}

This research was conducted using a web-based survey which was conducted from May to August 2011. The participation criteria are: an engineer with Indonesian cultural background; working in an engineering project or company, either under permanent or temporary contract; and working outside Indonesia.

297 people submitted responses to the survey. After review, 291 responses were found to be valid. The excluded responses were from people employed in universities or research institutions.

The gender distribution of participants is shown in Fig. 1. Numbers of participants by country of employment are shown in Fig. 2. Research participants based on type of industry are shown in Fig. 3. Research participants based on experience in multicultural work environment are shown in Fig. 4.

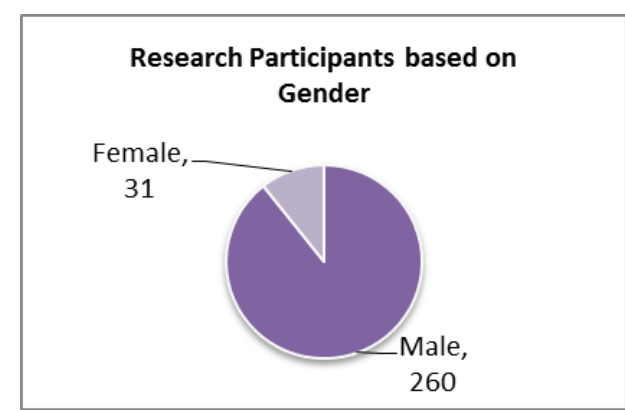

Fig. 1. Research participants based on gender

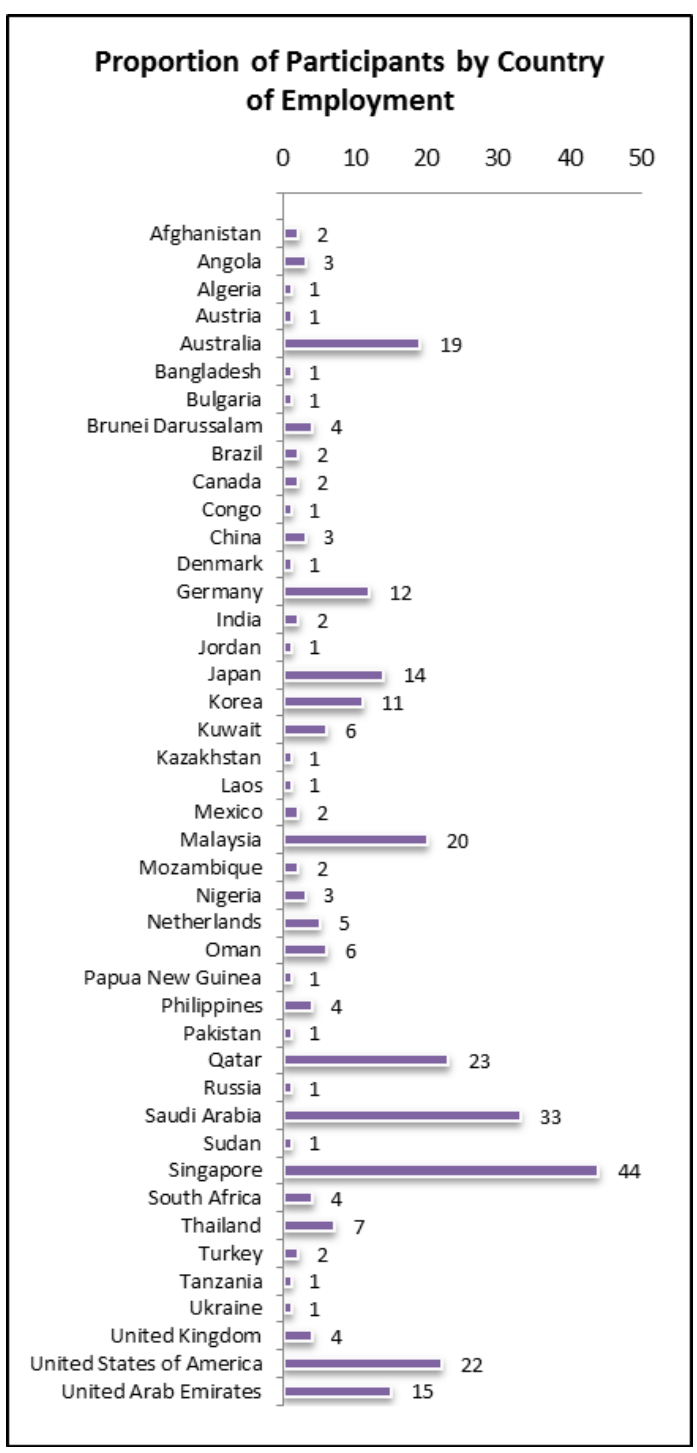

Fig. 2. Proportions of participants by country of employment 


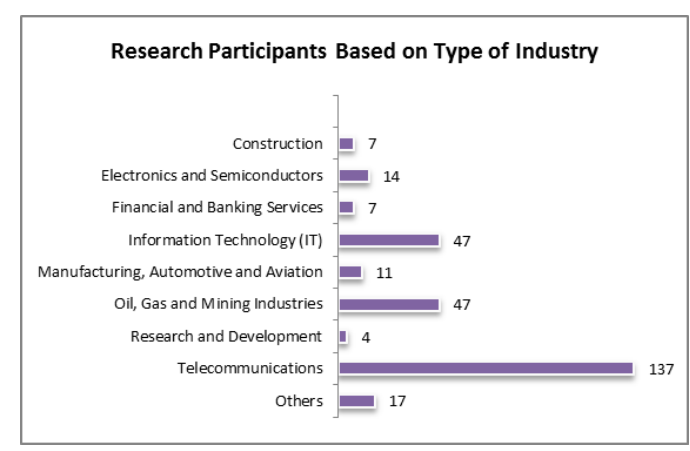

Fig 3. Research participants based on type of industry

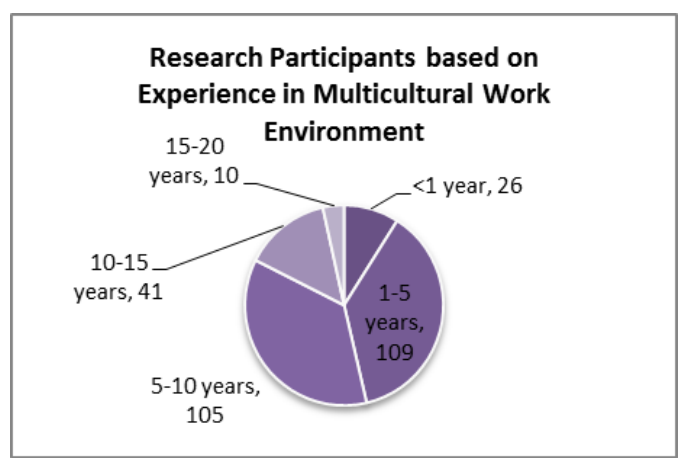

Fig 4. Research participants based on experience in multicultural work environment

\section{SySTEMS ENGINEERING PROCESSES AND CROSS- CULTURAL LEADERSHIP}

\section{A. Elements of Systems Engineering Processes}

The international standard describing the systems engineering processes associated with the system lifecycle is ISO/IEC 15288 [4]. This standard is used as the basis of the INCOSE (International Council on Systems Engineering) Systems Engineering Handbook [5], which in turn is the foundation of the INCOSE systems engineering certification program [3].

ISO/IEC 15288 divides the processes to support the system lifecycle into four groups: agreement; organizational projectenabling; project; and technical processes. The description of each process is as follows.

\section{1) Agreement processes}

Agreement processes are the activities for organizing agreement between the acquirers and suppliers of systems. In agreement processes, there are two main processes: acquisition and supply process. These processes concern how the organization performs the work of deciding with whom to perform business and how agreements which form the basis of the business are achieved.

\section{2) Organizational Project-Enabling Processes}

The purpose of Organizational Project-Enabling Processes is to ensure the entire project resources are appropriate to achieve the expectations of the organization elements involved. These processes set up the project atmosphere and generate a strong business framework. The processes start with a life cycle model, infrastructure, and project portfolio management processes. To ensure human resources availability and competency, human resource management is also needed. The last process is quality management to ensure customer satisfaction with guaranteed product and service quality.

\section{3) Project processes}

Generally, project processes concern planning and managing the project. Project planning can be modified during the technical processes, supported by a work breakdown structure, configuration management records, and risk control in project management to maintain the achievability of the project purposes.

\section{4) Technical processes}

Technical processes concern design, development and implementation of the system. The technical processes are built from project requirements that will be analyzed for their validity, consistency, desirability and achievability in a certain time period. The final outcome is the development, integration and implementation of the product in the user environment. Maintenance and disposal are also included in the technical processes.

\section{B. Indonesian Expatriate Engineers' Cross-Cultural Leadership Experience}

All the participants were working in a culturally diverse environment. Those with familiarity with a multicultural work environment found that cross-cultural adaptation in their workplace was not a major challenge for work performance. They found that the multicultural team helped them to complement each other to improve project achievement and quality. These findings are supported by Page's work that shows that diversity in a project team can lead to improved outcomes [6].

In some cases the limited cross-cultural ability of engineers may reduce project performance rather than lead to improvement. What is leadership? Leadership defined is a role of influencing groups of people or organizations in terms of task and objectives, commitment and fulfillment of target achievement, group/organization identification and culture [7]. Cross-cultural leadership is defined as leadership (as defined above) in a multicultural work environment. General duties of the leader are to manage the achievements of the project goal and manage job distribution among the team members under the leader's authority. The two main responsibilities should be balanced and maintained [8]. In cross-cultural leadership power distance, one of Hofstede's cultural dimensions, takes an important role [9]. The relationship between the leader and follower is influenced by the perception about power distance based on their cultural background. An example of inappropriate leadership action in cross-cultural leadership is when the leader uses his/her cultural background based leadership style in a multicultural team work [10]. Therefore, in multicultural working environment, social-oriented leadership skills are needed to achieve project success. These skills include conflict resolution skills, interpersonal and group consideration, social sensitivity, diplomacy skills, and communications [11]. 


\section{CONFlict Management In The Multicultural WORK TEAM}

The research participants were asked how the project leaders resolved conflicts in their multicultural project team. There were five possible responses to this question, from which the interviewee was to select only one, were:

A. Based on the uniqueness of each individual,

B. Based on the cultural background of each person,

C. Based on existing rules,

D. All project team members are treated equally, or

E. Compromising conflicts with other parties/ mediator.

Each answer option in this question has a background originating in the first phase of this study, which were interviews with 18 Indonesian expatriate engineers. It was found that the engineers mainly offer those five factors in conflict resolution [2, 3]. The first option that conflict is resolved based on the uniqueness of each individual is found because the project leader realized the subordinates have unique personal background, such as family, education, etc. The project leader adjusts the leadership style to fit the team members' personal background.

The second option that conflict is resolved based on the cultural background of each person is similar to the first option, but in builds on cultural background.

The third option in conflict resolution is that the leader resolves the conflict based on the existing rules of the organization. This option is the most common. The impact is that conflict resolution, despite of the cultural or personal background of the parties is based on the leader's use of organizationally conferred authority to solve the problem using the regulations in the project documentation.

The fourth option is that if any conflict happened; all project team members will be treated equally regardless of their position or other factor. In this option, the ability of the leader to maintain fairness among the subordinates is applied [12].

The last option is that the leader needs to use a mediator. In this option, the leader chose not to use his/her leadership or conferred authority in conflict resolution but involved others such as the human resources department. The survey results are shown in Fig. 5.

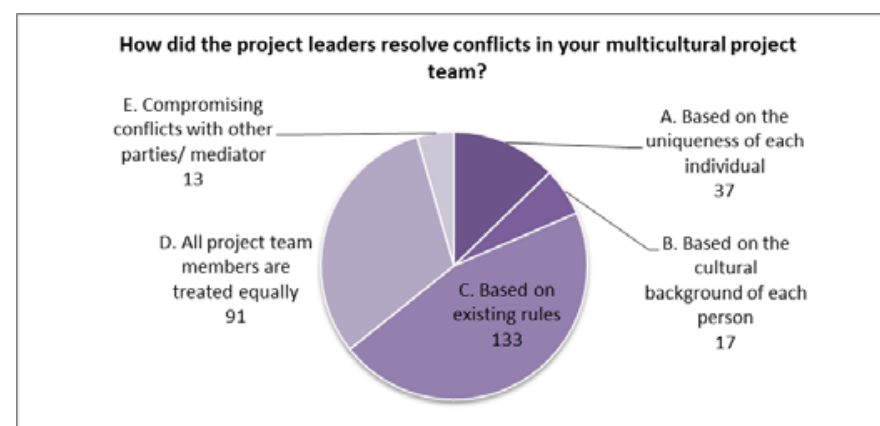

Fig 5 Conflict resolution strategy by the project leader in multicultural project teams
Fig. 5 shows that $45.79 \%$ of the respondents answered that the project leader resolved conflicts in the multicultural project team by using existing rules written in the project guidelines. This reveals that most project leaders preferred to make judgments in the multicultural working environment based on existing rules rather than considering the cultural background of the team members. This result reflects a different result than was obtained in the pilot study interviews. The research participants were asked this question:

The managements of conflicts are also an issue in the Human Resource Management Process. Do you think the project leader tends to manage it based on the uniqueness of each individual?

From the interview quote, it was found that conflict resolution was based on the uniqueness of each individual [2, 3]. This was noted in one of the responses:

As project leader, I realized that my subordinates have the uniqueness of each according to their cultural background. Therefore, I always re-solve the conflict in my project team by organizing my approach to each individual. (E1A2/RASMA)

The difference would appear to result from the survey requiring selection of a single response in contrast to the free-form response permitted in the interviews.

\section{DeCision Making In Multicultural WORK TEAM}

Decision making processes in the cross cultural working environment are related to cross-cultural leadership. The research participants were asked about how the team members contribute their ideas to the leader's decision in risky situations. They could choose multiple options below:

A. The decision is entirely in the hands of leader/acting autocratically

B. The decision is the responsibility of all team members

C. Subordinates feel reluctant to give feedback to their superiors

D. The decision is always made by collaboration of the leader's and members' ideas

E. The leader encourages the subordinates to contribute in a formal way, such as by analysis

Each option in this survey question has a background for its presence. From the first phase of this study, the interviews with 18 Indonesian expatriate engineers, it was found that the engineers primarily described the five factors in the leader's approach in decision making [2, 3]

The first option, that the decision is entirely in the hands of leader/acting autocratically is present because it was found that some project leaders decide to handle all the problem solving in the project by imposing their authority.

Conversely, the second option, that the decision is the responsibility of all team members reveals a process of dynamic team work where all the team members are responsibile to contribute in the decision making process.

The third option is that the circumstances in the project team make the subordinates feel reluctant to give feedback to their superiors. This option commonly happened in project teams with a wide gap of power-distance between the leader and 
subordinates [9]. These could also vary with company size and/or structure, as well as the nature of the systems to be engineered.

The fourth option is that the decision is always made by collaboration of the leader's and members' ideas. In this option, social-oriented leadership skills are applied [11].

The last option is that the leader encourages the subordinates to contribute in a formal way, such as by analysis, which also involves leadership skills of the leader.

The survey result, in which the research participants were allowed to check more than one option, is shown in Fig 6.

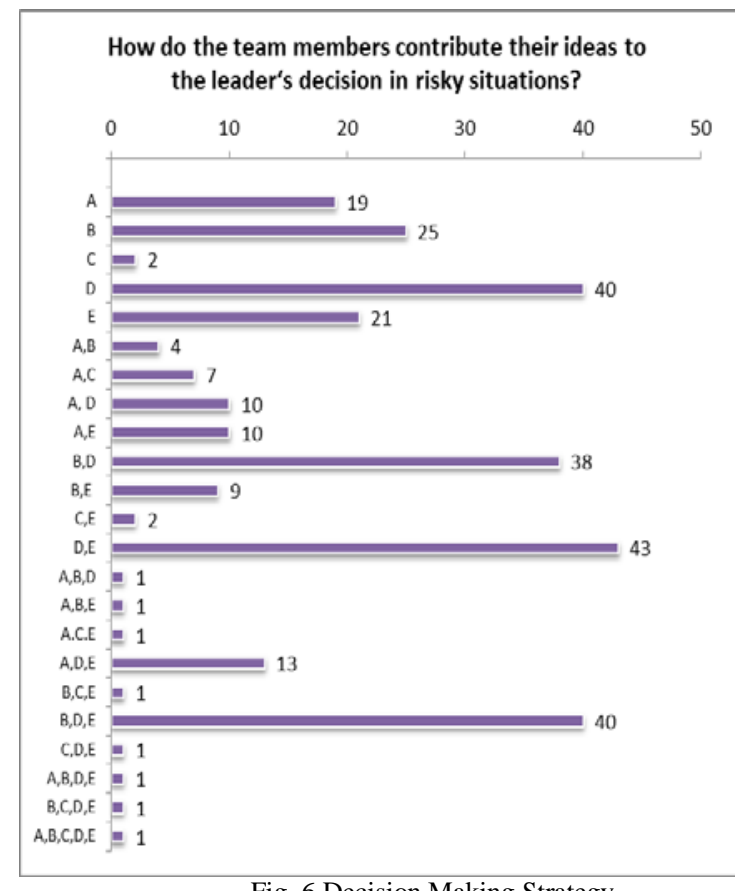

Fig. 6 Decision Making Strategy

In Fig.6. above, the sum of participants who chose D (40), A,D (10), B,D (41e), D,E (44) and B,D,E (40) is high, being 175 of 291 participants. Therefore in this analysis, it is clear that option $\mathrm{D}$ that decisions include collaboration of the leader's and members' ideas was dominant. Including the combination options we found that the important decisions in the project team were made collaboratively, combining the leader's ideas and members' contribution in analyzing the supporting ideas.

\section{COMPLETENESS AND PERFECTION OF THE PROJECT VS RELATIONSHIPS BETWEEN THE TEAM MEMBERS}

The research participants were asked an open-ended, text based, question about what they individually believe to be the most important thing for their organization. The result from this question can be categorized into three main groups as follows:

- The first group were those who answered that the completeness and perfection of the project is the most important, and the reasons for this answer trifold: result/goal orientation, profit orientation and lower importance of team relationship.

- The second group were those who answered that the most important thing in a project is the relationship between the team members. They offered three main reasons: work productivity, leadership, and solid teamwork. These reasons, notably, can be argued to be causal factors to support successful completion of projects.

- The third group were those who answered that both the completeness and perfection of the project and the relationship between the team members contribute equally to a successful project.

The result for this question can be seen in Fig. 7.

Which one is the most important for the organization?

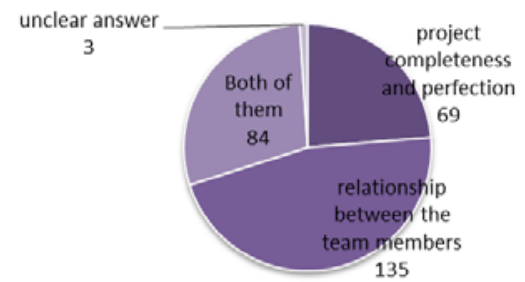

Fig. 7.Which team leadership orientation is the most important for the organization?

\section{A. Completeness and perfection of the project}

As shown in Fig.7. 69 answered that the completeness and perfection of the project is the most important thing for the organization. These engineers explained why they chose this option.

\section{- Result/goal orientation}

The main objective of a project is achieving the project goal with a high quality result. The objective is set at the beginning of the SE processes including requirement elicitation, analysis and verification, design, review and planning, and is implemented in the later stages of production/construction, system verification and validation, operational use, system support and control, and through to disposal of the system [4, 13-15].

In this survey a number of engineers explained the reasons for their perception that the most important thing in the project is achieving the project goal. Some quotations follow.

Actually, it is not only the perfection of the project, but the end result of that project. In the real world rarely found perfect project in any industry. The final goal is that the project was accomplished in accordance with all targets. (E47INTL/MLD)

I think complete and perfect project is the most important thing for organizations. The reason is because essentially we have to deliver the project. So the most important things are all the circumstances that support the perfection of the projects. When the project goes smoothly, in general the relationship between 
team members will also be good because each of them can appreciate the contributions of team members. (E69SGIT/MLC)

Project completeness and perfection is the most important thing. This is related to the professionalism which can be implemented by good team work. Targets and objectives of the project should be achieved by team work and professionalism. (E189SATL/MLE)

\section{- Profit orientation}

The objective of the company or project is to make profit from what is provided. This becomes the base of the research participants' answer on why the completeness and perfection of the project is more important than the relationship among the team members. The engineers explained in the following survey quotations.

The most important thing is the completeness and perfection of the project. That is because we paid for the success of the company, rather than building relationships. (E42SATL/MLB)

Viewed from the organization side, the complete and perfect project is more important. This is because it directly receives the effects of the financial side (profit or cost-savings). Staffs in this industry are required to have high professionalism and good instincts for cooperation. (E254MYOM/MLB)

The project is complete and perfect, that is more important than the other because an organization will be judged based on financial performance. Relationships between members are supportive, but cannot be formal success criteria. (E296SGIT/MLB)

\section{- De-emphasis on team relationship}

Some of the research participants are expatriate engineers employed on a contract basis. Their job is mainly accomplishing the project's objective in a certain country and then they will relocate to another country for a different project in the same company. This circumstance caused these engineers to rate the relationship between team members as less important than achievement of project objectives. The engineers explain as below.

A complete and perfect project is more important. This is because of the mobility the staff at the U.S. is relatively high (ease to move from one firm to another). (E174USIT/MLD)

The most important is project completeness and perfection, although in reality this rarely happens. However, projects with a fairly clear documentation can continue running even though with team member's change in the process of implementation. (E207DEIT/MLB)

Another reason for the lower importance of team relationships is the inequality of salary or race in multicultural work teams. This was noted in one of the responses:
I choose the first choice, complete and perfect projects. In my opinion, when we work overseas we cannot expect to work in harmony, because the inequality must always exist, for example: the problem of salary or race. Working overseas will surely always be horizontal or vertical conflict of interest. (E176AOOM/MLD)

\section{B. Relationships between the team members}

In this question, 135 engineers answered that the most important thing in organizations is the relationship between team member instead of the project completeness and perfection. Their reasons can be categorized to three main categories: work productivity, leadership, and solid teamwork.

\section{- Work productivity}

Some of the research participants who said that relationships between team members are more important than project completeness and perfection explained that good relationship among team member support the productivity of the team in achieving the project goal. Several examples of this view follow.

The relationships within the team are more important because if the members have good communication among them, it will increase the productivity and effectiveness in work. (E13USTL/MLB)

The relationship between team members is more important. It was because the convenience to work in an harmonious team will support the achievement of synergy, so that everyone can contribute positively in the interest of the project, for example, projects can be completed on time with good expected results. (E277OMOM/MLB)

The relationship between team members [is more important]. [It was] because with the harmonization of the good relationships, the people in the team will be more motivated to work properly and seriously. There is a sense of mutual help and mutual aid. The discussion will run better because of each other open. Conducive conditions will ultimately contribute to the ability of teams to deliver the work. (E154MYOM/MLA)

\section{- Leadership skills}

As been discussed in a previous section leadership skills are important for success of a project. In this part, cross-cultural leadership skills are also shown to be important in a project because they are related to the importance of team relationships as a contributing factor to project success. Some explanations of this issue are below.

Certainly the most important thing is the relationship between the team members. Within a multicultural workplace, where we work in accordance with the SOW (Scope of Work) just by following the rules of the project, so a major priority is leadership by the appointed project leadership. (E244AETL/MLA)

The relationship between team members is more important. Backgrounds of team members in a project 
are generally diverse, so the relationship between members is vital to the success of the project. This is one of the most critical tasks for the project managers. Experienced project managers will always focus on being good leaders for the project members. In a good relationship the project team will run more easily because each team member is able to communicate effectively for the purposes of the project. (E77AUOM/MLB)

In an organization, the relationship between leaders and subordinates should be cohesive and have two-way open communication. Good communication is expected to overcome existing constraints in an organization or department. (E273SGIT/MLC)

\section{- Solid teamwork}

The last reason for the importance of relationships between team members is because solid teamwork can be developed and with this solid teamwork the project will run well and the objective can be achieved.

The relationship between team members is the most important thing, because completeness is not enough without good relationships supported by fellow team members. Conversely, if there is a good relationship between team members, then many problems can be solved, because of the communication, mutual respect, and good cooperation. (E28AUOM/FMD)

Relationship among team members is more important. The good relationship between team members will provide comfort for each member and each individual communication will run better, so that each can contribute optimally. (E72AETL/MLC)

For multicultural teams relations between team members is very important, because communication and commitment are needed in running the project, so target would be achieved. (E121MYIT/MLB)

From the survey quotations it was an interesting finding that some argued that too good relationships do not always benefit the project. If the people get on too well together there is a significant risk that they will not be sufficiently critical of each other's work to ensure good project outcomes but rather the office would become something of a social club to which they enjoy going and everyone does what it takes to have a nice day with the club, as described in this quote:

I would say that I do not need smart people; but I need people that can work together as a team. Relationships that are too good could result in too much tolerance instead and will interfere with the purpose (goals) of the project. (E227OMOM/MLE)

C. Combined answers: Completeness and perfection of the project and relationships between the team members

From the survey results, 84 engineers answered that an emphasis on a combination of completeness and perfection of the project and relationships between the team members are useful for the project or organization. These arguments can be seen from the following quotations.

Both actually have the same level of importance to an extent. Having a $100 \%$ perfect plans and complete project is almost impossible. Having a $100 \%$ great relationship among the team member is also considered to be impossible. Nevertheless, I believe we still need to have both at good conditions. To illustrate, we need $80 \%$ good plans as well as $80 \%$ good relationship among members in order to deliver a good result for the project. (E248JPFB/MLB)

I think both are important. Project completeness and perfection will not succeed if the relationships between superiors and subordinates are not harmonious. Many cases happened in many companies where a PM (Project Manager) imposes unrealistic work deadlines on subordinates. Another case is when a superior who had lack of respect for his subordinates' hard work. These cases result in decrease of employee loyalty to the job. Consequently, it will cause a lot of project delay, less quality of the result, etc. So I think both are very important (E259MYIT/MLA)

\section{CONCLUSIONS}

Systems engineering processes performed by Indonesian expatriate engineers in various engineering projects require cross-cultural leadership competence for the engineers to maximize the quality of the project performance.

Several issues were identified as factors influencing crosscultural leadership including conflict resolution and decision making. Engineers were also asked about their perception of how the completeness and perfection of the project or the relationships between the team members ranked in importance to the organization.

This paper reports that, as perceived by Indonesian engineers, conflicts in the project team mostly were resolved based on existing rules rather than considering the cultural background of the protagonists. The important decisions in the project team were made by collaboration of the leader's ideas and member's contributions in analyzing the supporting ideas.

Leadership skills in a multicultural context are also shown to be important in a project because they are related to the importance of team relationships as a contributing factor to project success.

Other results from this study are that the relationships between team members are often seen as being of great importance to the organization rather than direct emphasis on project completeness and perfection.

Engineers suggested that a combination of completeness and perfection of the project and relationships between the team members are valuable for the project or organization in implementing SE processes and their implication for the improvement of cross-cultural leadership capability.

Finally, for future work, the data about diversity in project teams enables a cross-correlation analysis between 
background (experience, demographic, and type of industry) of engineers and the findings reported here about crosscultural leadership.

\section{ACKNOWLEDGMENT}

I.S. Windiarti thanks the Government of Indonesia for funding of this research through a DIKTI Scholarship.

\section{REFERENCES}

[1] V. Suutari, K. Raharjo, and T. Riikkila, "The Challenge of Cross-cultural Leadership interaction: Finnish Expatriates in Indonesia," Journal of Career Development International, vol. 7, pp. pp 415-429, 2002.

[2] I. S. Windiarti, T. L. J. Ferris, and M. J. Berryman, "System Engineering Processes and Cross-Cultural Perception of Expatriate Indonesian Engineers," presented at the 5th Asia-Pacific Conference on Systems Engineering (APCOSE 2011), Seoul, Korea. , 2011.

[3] I. S. Windiarti, T. L. J. Ferris, and M. J. Berryman, "Technology and Knowledge Sharing Strategy in Systems Engineering Practice performed by Indonesian Expatriate Engineers," presented at the The IEEE International Conference on Industrial Engineering and Engineering Management, Singapore, 2011b.

[4] ISO/IEC 15288, "Systems and Software engineering System Life Cycle Processes," 2008.

[5] INCOSE, System Engineering Handbook, 2000.

[6] S. E. Page, The Difference: How the power of diversity creates better groups, firms, schools, and Societies. New Jersey: Princeton University Press, 2007.
[7] G. Yukl, "Managerial Leadership: A Review of Theory and Research," Journal of Management, vol. 15, p. 251, 1989.

[8] E. Szewczak and C. Snodgrass, Managing The Human Side of Informaton Technology: Challenges and Solutions. United States of America: Idea Group Publishing, 2001.

[9] G. Hofstede, "The Cultural Relativity of organisational Practices and Theories " Journal of International Business Studies, vol. 14, pp. pp. 75-89, 1983.

[10] R. Mead, Cross-cultural Management Communication. West Sussex, England: John Wiley \& Sons, Inc., 1990.

[11] O. B. Ayoko and C. E. J. Hartel, "Cultural Diversity and Leadership: A conceptual model of leader intervention in conflict events in culturally heterogenous workgroup," International Journal of cross-Cultural management, vol. 13, pp. pp.345-360, 2006.

[12] A. Nahavandi, The Art and Science of Leadership. United States of America: Prentice Hall 1997.

[13] B. S. Blanchard and W. J. Fabrycky, Systems Engineering and analysis, 3rd Ed. ed.: Prentice-Hall Inc., 1998.

[14] D. W. Oliver, T. P. Kellihet, and J. G. Keegan, Engineering Complex Systems with Models and objects. New York: McGraw-Hill, 1997.

[15] IEEE, "IEEE Std 1220-1998 IEEE Standard for Application and Management of the Systems Engineering Process," ed. New York, USA: The Institute of Electrical and Electronics Engineers, Inc., 1999. 